\title{
Alloparental behavior in the highly vocal Lusitanian toadfish
}

\author{
Andreia Ramos ${ }^{\mathrm{a}, *}$, Paulo J. Fonseca ${ }^{\mathrm{a}}$, Teresa Modesto ${ }^{\mathrm{b}}$, Vítor C. Almada ${ }^{\mathrm{c}}$, Maria Clara P. Amorim ${ }^{\mathrm{c}}$ \\ a Departamento de Biologia Animal, Centro de Biologia Ambiental, Faculdade de Ciências da Universidade de Lisboa, Bloco C2 Campo Grande, 1749-016 Lisbon, Portugal \\ ${ }^{\mathrm{b}}$ Centro de Ciências do Mar, Universidade do Algarve, Edifício 7, Campus de Gambelas 8005-139 Faro, Portugal \\ c Unidade de Investigação em Eco-Etologia, I.S.P.A. - Instituto Universitário, Rua Jardim do Tabaco 34, 1149-041 Lisbon, Portugal
}

\section{A R T I C L E I N F O}

\section{Article history:}

Received 9 May 2012

Received in revised form 28 June 2012

Accepted 4 July 2012

Available online 31 August 2012

\section{Keywords:}

Alloparental care

Batrachoididae

Egg survival

Hormone circulating levels

Sound production

Territorial defense

\begin{abstract}
A B S T R A C T
In many fish species in which males guard nests with their eggs, parental care directed to genetically unrelated offspring may arise for example from nest takeovers or cuckoldry. Lusitanian toadfish (Halobatrachus didactylus) has exclusive male parental care and face intensive nest competition during the breeding season that may lead to care of foster eggs. Males of this species use visual displays and sounds when defending their nests frequently resulting in expulsion of the intruder without escalated confrontation. In this study we intended to investigate the existence of alloparental care in Lusitanian toadfish, a behavior whose adaptive significance is still poorly understood. Fish were randomly assigned to three different treatments: parental males in nests with their eggs, parental males with foster eggs and parental males without eggs. Nests with eggs with no nest holder or with females were used as controls. We performed three territorial intrusions over periods of 15 days and observed the acoustic and visual behaviors of residents and intruders. Egg survival was tallied from nests' photographs in all groups. Circulating steroid levels were measured in the three test groups and in another set of non-manipulated males. There were no differences in acoustic and visual territorial defense behaviors among treatments. Egg survival was similar between males (parental and alloparental) and significantly higher than in nests with no nest-tender. Females presented intermediate egg survival. All groups presented similar levels of testosterone and alloparental males showed higher 11-ketotestosterone levels but within the range of levels observed in non-manipulated males. Cortisol levels were similar in all male groups suggesting that experiments did not increase fish stress. The present results suggest the existence of alloparental care in this species.
\end{abstract}

(c) 2012 Elsevier B.V. All rights reserved.

\section{Introduction}

Parental care evolves when the benefits of taking care of the offspring outweighs the costs (Farmer and Alonzo, 2008). Parental care is often given by females (as in mammals), and contribute to a differential reproductive effort between the sexes (Alcock, 2009). However, paternal care is the most common form of parental care in teleost fishes with external fertilization (Blumer, 1979) and has evolved due to the lower cost of care for males than for females (Gross and Sargent, 1985). When females provide parental care, they not only lose mating opportunities but grow less and take longer to produce new eggs due to reduced feeding and extra energy spent in care. In contrast, costs of paternal care are reduced in fish as males often need to defend a territory/nest to attract females to mate with, and can attract more mates while caring for existing broods (Alcock, 2009). In fish, parental care consists in preparing and defending nests or territories, to guard, clean and aerate the eggs and embryos, as well as to provide nutritional support for the brood to become independent (Gross and Sargent, 1985).

\footnotetext{
* Corresponding author. Tel.: +351217500000.

E-mail address: andreiamcramos@gmail.com (A. Ramos).
}

When the competition for nests or mates is intense, care for foster offspring (i.e. alloparental care) may result from nest takeovers or from increased sneaking fertilizations. Alloparental care is also observed in group-living communal or cooperative breeders (Taborsky, 1985). While the adaptive advantages of parental care to their own offspring are obvious, the care for offspring of other males can be considered maladaptive (Smith and Wootton, 1995; Trivers, 1972). Indeed, alloparental care can be considered a mistake (lack of foster egg recognition) or a by-product of lack of alternatives. However, alloparental care may also bring direct benefits. For example, males with foster eggs can be more attractive to females (eggs in the nest effect; e.g. Rohwer, 1978) or benefit from decreased egg predation due to confusion or dilution effects (Wisenden, 1999). Despite the advantages of alloparental care there are also many disadvantages such as increased expenses of care, reduced space for new eggs, and higher risks of egg infection (Constanz, 1985; Manica, 2002). Studying the existence of alloparental care in different species will allow to better understand its adaptive role and the underlying behavioral and physiological mechanisms.

Batrachoididae males, toadfish and midshipmen, defend their nests in the reproductive season. These species may present alternative reproductive tactics exhibiting two male morphotypes. In such 
cases only type I males or "singing males" use acoustic signals to attract mates, providing parental care to multiple clutches of eggs (Brantley and Bass, 1994; Gray and Winn, 1961; Modesto and Canário, 2003). In contrast, type II males neither build nests nor acoustically advertise to females, but instead satellite or sneak spawn to steal fertilizations from type I males (Brantley and Bass, 1994). During the period that type I males spend defending their nests and providing parental care, they have fewer opportunities to feed, decreasing their physical condition (Modesto and Canário, 2003; Sisneros et al., 2009). Because in these fish allopaternal care could exist likely due to frequent nest takeovers and parasitic fertilizations and since parental care is prolonged and costly, they provide excellent models to study the existence and the adaptive value of allopaternity.

Our aim was three-fold. First, we aimed to study the existence of allopaternal care in Lusitanian toadfish, by comparing both nest defense under territorial intrusions and egg survival between clutches guarded by parental males and alloparental males that were given a nest with $100 \%$ foster eggs. Second, we wanted to verify if the use of agonistic behavior during nest defense, including sound production, differed between males with different genetic relation to offspring. Finally, we checked for physiological differences (androgen and cortisol levels) that likely underlie territorial defense behavior including sound emission (Remage-Healey and Bass, 2005). We predicted that if males do not show alloparental care, (1) parental males would defend their nests more aggressively than alloparental males and would show higher levels of androgens. We also predicted that (2) parental males would have higher offspring survival.

\section{Materials and methods}

\subsection{Study species}

The Lusitanian toadfish, Halobatrachus didactylus (Bloch \& Schneider), is a member of the Batrachoididae family, and is a benthic fish that inhabits estuaries and coastal zones of the Eastern Atlantic and the Mediterranean, usually found partly buried in soft sediment or concealed in rock crevices (Roux, 1986).

Between May and July (reproductive season of Lusitanian toadfish in Portugal), breeding males defend their nests under rocks in shallow waters and attract females to spawn with advertisement calls (boatwhistles) until the roof of the nest is full of eggs and embryos (dos Santos et al., 2000). The eggs are attached to the roof by an adhesive disk, and guarded by a male until the brood is free-swimming (Roux, 1986). During this period (c. 30 days), the competition for shelters in shallow waters increases (Amorim et al., 2010) and shelter owner substitutions occur, including in nests with eggs (Vasconcelos et al., 2010). Nest-holding males defend their nests with the emission of agonistic boatwhistles, frequently resulting in the expulsion of the intruder, or with chases and bites when fights escalate (Vasconcelos et al., 2010).

\subsection{Test subjects and maintenance}

We used an experimental procedure similar to that conducted by Vasconcelos et al. (2010). Concrete nests (internal dimensions: $50 \mathrm{~cm}$ long, $30 \mathrm{~cm}$ wide and $20 \mathrm{~cm}$ height) with a hemicylinder shape capped at one end were placed in the Tagus River estuary (Military Air Force Base 6, Montijo, Portugal; $38^{\circ} 42^{\prime} \mathrm{N} ; 8^{\circ} 58^{\prime} \mathrm{W}$ ). These nests were readily occupied by toadfish in the breeding season and were only exposed to air during spring low tides, when males could be collected. Experimental males (type I) were maintained in round stock tanks (plastic swimmingpools, $2 \mathrm{~m}$ diameter and water depth c. $0.5 \mathrm{~m}$ ), near the intertidal toadfish nesting area. Stock tanks were provided with shelters (roof tiles) to allow them to develop territorial behavior. Experimental tanks were similar to the stock tanks but with $2.5 \mathrm{~m}$ diameter and had two nests $50 \mathrm{~cm}$ apart from the border. All tanks were under a shadow net cover held circa
$170 \mathrm{~cm}$ high to prevent excessive solar water heating. Water temperature varied from 19 to $26^{\circ} \mathrm{C}$, within the range of the estuary water temperature variation during the same period. The renovation of water was done every 2-3 days, by pumping water directly from the estuary. The light cycle was natural as tanks were outdoors.

\subsection{Territorial experiments}

Two subjects were placed in each experimental tank and given a period of acclimation of $48 \mathrm{~h}$ before the beginning of the observation. Subject fishes were randomly assigned to three different treatments: (1) alloparental males, i.e. parental males that were given nests with eggs from another male (AP), (2) parental males in nests with their own eggs (PWE), (3) parental males that were given nests with no eggs (PNE). We also used two control groups in experimental tanks. One consisted of nests with eggs but with no males (ENM), to control for egg survival in nests in the same conditions as those of AP and PWE groups but with no nest holder to provide parental care. The other control group comprised nests with eggs occupied by a female (FWE). The latter group aimed to check the effect of the simple presence of a fish in egg survival since females do not provide parental care.

We used 36 residents ( $n=10$ PNE; $n=14$ PWE and $n=12$ AP) kept in pairs (18 pairs) in the experimental tanks. Each pair of resident males was submitted to 3 intrusions. We used two territorial males in each tank to simulate a more realistic scenario since this species lives in aggregations (Amorim et al., 2010). Resident males were always different in each experiment and varied in total length $(\mathrm{TL}=35-47 \mathrm{~cm})$ and in body mass (498-2010 g). Intruders were never used twice in the same day and ranged 32-50 cm in total length (TL) and 477-1915 g in body mass. Fish were marked with small cuts between the fin rays to insure identity during trials. Marking did not cause any measurable change in the fish behavior.

At the start of each trial we inserted a male intruder in the tank, and registered all behaviors and sounds produced by the residents and the intruder during $30 \mathrm{~min}$. After this period we placed a new male (second intruder) in the tank, and registered all behaviors of the four fish for another period of $30 \mathrm{~min}$.

We carried out three intrusion trials (as above) with the same residents at the first, the fifth and the tenth day of the experiment to investigate any possible changes in the territorial defense that could be caused by physiological changes due to the treatment effect. We hypothesized that assigning a nest with $100 \%$ foster eggs or with no eggs to parental males (with recent broods) could cause physiological and behavioral changes that could possibly not be expressed immediately.

\subsection{Behavior recording}

Fish visual behavior, i.e. lateral displays (full extension of dorsal and caudal fins in antiparallel position) and frontal displays (full extension of pectoral fins and opercula), was assessed through direct observation and registered on paper. For residents we registered the frequency of non-escalated behaviors such as mouth opening with the extension of pectoral fins and opercula and escalated behaviors including bite attempts and mouth-mouth fight (Vasconcelos et al., 2010). For the intruders we tallied the number of approaches and attempts to enter the nest. We defined approaches when the intruder was at least within a body length from the nest and we considered attempts to enter the nest when the intruders managed to get part of the body inside the nest.

To record the acoustic signals we placed one hydrophone (High Tech 94 SSQ Gulfport, MS, USA; frequency range: $30 \mathrm{~Hz}-6 \mathrm{kHz}, \pm 1 \mathrm{~dB}$; voltage sensitivity: $-165 \mathrm{~dB}$ re. $1 \mathrm{~V} / \mu \mathrm{Pa}$ ) in front of each nest at about $10 \mathrm{~cm}$ both from its entrance and from the tank bottom, attached to an wooden rod positioned over the tank. The two hydrophones were simultaneously recorded to a laptop connected to a 2 channel USB audio capture device (Edirol UA-25, Roland, Japan; 16 bit, $6 \mathrm{kHz}$ acquisition rate 
per channel), controlled by Adobe Audition 2.0 (Adobe Systems Inc., San Jose, CA, USA). Acoustic behavior during trials was also monitored with headphones and registered on paper.

The acoustic signals were analyzed and quantified using also Adobe Audition 2.0. We tallied the number of boatwhistles produced by residents as well as, grunts and other sounds that occurred less frequently. Recordings of sonic muscles contraction activity during some experiments showed that typically only residents produce boatwhistles during territorial intrusions (J. Jordão, personal communication).

\subsection{Hormones assays}

To analyze the levels of testosterone (T), 11 ketotestosterone (11-KT) and cortisol (Cort), we used 4 different groups: AP, PWE, PNE and non-manipulated (NM) males that occupied spontaneously the artificial nests placed in the estuary and that were not used in the experiments. The NM group presented a size similar to the other experimental groups (TL ranged $37-48 \mathrm{~cm}$ ).

Immediately after the last observation (3rd intrusion), blood samples were collected. As soon as the nest was overturned, the male was taken off the nest and immediately anesthetized in a box with sea water and MS-222. Blood samples were collected from the caudal vein using heparinized syringes, usually within $4 \mathrm{~min}$ from overturning the nest. Plasma was immediately separated by centrifugation $(5 \mathrm{~min}$ at $5000 \mathrm{RPM}$ ) and stored at $-20{ }^{\circ} \mathrm{C}$ until steroid quantification by RIAs (radioimmunoassays). The procedure to analyze T, 11-KT and Cort levels in plasma was similar to that conducted by Vasconcelos et al. (2012). After blood sampling, fish were allowed to recover from anesthesia and were returned to the estuary.

\subsection{Eggs survival}

We photographed and counted the eggs in each nest at the beginning and end of each experiment to calculate the percentage of egg survival for AP and PWE males, for nests with no males (ENM) and for nests with females (FWE).

\subsection{Statistical analysis}

Statistical analyses were performed with STATISTICA for Windows (v. 9.0, StatSoft, Inc. 2009). Parametric tests were only performed when data were normally distributed and variances were homogeneous.

We compared the number of acoustic and visual behaviors among treatment groups (independent factor with 3 levels, AP, PWE and PNE) and among intrusions trials (repeated measures) using repeatedmeasures ANOVA. We used resident male total length as a covariate since it might influence contest behavior. However, since the effect of male length was not significant the covariate was removed in further analyses. We checked that the different treatment groups received a similar amount of interactions by intruders (approaches and nest intrusions) also with repeated-measures ANOVA. The number of times the intruders interacted with the resident males did not differ among treatment groups (repeated-measures ANOVA: $F_{(2,33)}=0.14, \mathrm{P}>0.05$ ) or among the three intrusions (repeated-measures ANOVA: $F_{(2,66)}=0.17, \mathrm{P}>0.05$ ) ensuring that any possible behavioral differences among groups were due to treatment and not to intruder behavior.

To compare hormones levels (T, 11-KT and Cort) among treatment groups (AP, PWE, PNE and NM) we used non-parametric Kruskall-Wallis tests. Differential egg survival for AP, PWE, ENM and FEW groups was tested with a one-way ANOVA.

\section{Results}

We observed that $71 \%$ of intruders ( $n=108$ in total) approached the nests in less than $3 \mathrm{~min}$. Intruding behavior (totalling 546 events) consisted mostly of approaches to a nest (74\%). Attempts to enter a nest were less frequent (26\%). From these, intruders succeeded in entering the nest only 16 times (11\%): 6 in nests with AP males, 6 in nests with PWE males and 4 in nests with PNE males. In the 6 attempts to enter PWE nests, 4 resulted in nest takeovers. In the other groups (AP and PNE) no nest takeovers were observed.

Resident males typically responded to intruding events (79\%). In the case of an intruder's approach the most common reaction was sound production (91.5\%), and less frequently visual behavior (8.5\%). Similarly, when an intruder attempted to enter the nest the resident's main response was sound production (70\%). Thus, acoustic signaling, was the most common reaction to intrusion behavior. Moreover, boatwhistles were the most frequent sound emission, corresponding to $91 \%$ of the registered vocalizations as previously observed in this species (Vasconcelos et al., 2010). All subject males emitted boatwhistles in at least one of the 3 intrusion trials. There were no differences in both visual behavior and sound production among the different male groups (Table 1). Likewise, there were no differences in the visual and acoustic behavior along the three intrusion trials. Taking together, the analyses of our results point to the interaction between trial (repeated variable) and the treatment variables was not significant (Table 1). Taken together the data suggests similar motivation among AP, PWE and PNE males to defend the nest and no changes in territorial defense during the course of the experiment.

\subsection{Eggs survival}

Experimental nests taken from the estuary presented a variable amount of dead eggs ( mean $=12.0 \%$, range: $0.2-72.2 \%$ ), putting into evidence a considerable level of egg mortality in nature. At the end of the experiment egg survival was significantly higher in nests with males (AP, PWE) than in control nests without a nest holder (CRTL). Egg survival in nests with females was intermediate and did not differ from the other treatments (one-way ANOVA $F_{(2,36)}=2.31$; $\mathrm{P}<0.05$, Fig. 1).

\subsection{Hormone levels}

$\mathrm{T}$ and Cort levels did not exhibit significant differences among male groups (AP, PWE, PNE and NM) (Kruskall-Wallis test: $\mathrm{T}-\mathrm{N}=35$, $\mathrm{H}=4.47, \mathrm{P}>0.05$; Cort- $\mathrm{N}=35 ; \mathrm{H}=0.08, \mathrm{P}>0.05$; Fig. $2 \mathrm{~A}$ and $\mathrm{C}$ ). However, $11 \mathrm{KT}$ showed significant differences among groups (KruskallWallis test: $\mathrm{N}=35, \mathrm{H}=16.89, \mathrm{P}<0.001$; Fig. $2 \mathrm{~B}$ ) with the alloparental and non-manipulated males presenting higher circulating levels than parental groups (with and without eggs). 11KT levels of AP males and of other experimental male groups fell within the variability observed for the non-manipulated males sampled in nature.

\section{Discussion}

Most research about parental care has focused in understanding the fitness benefits of increased offspring survival and of the fitness costs to the parent through decreased future reproductive opportunities (Gross and Sargent, 1985). However the existence of alloparental care has received less attention (Constanz, 1985).

\section{Table 1}

Effects of group treatment (factor) and intrusion trials (repeated measures variable) on non-escalated (exhibitions) and escalated agonistic visual behavior and on sounds made in response to intruders. Data concerning sound production and non-escalated visual behavior were log-transformed to meet ANOVA assumptions.

\begin{tabular}{lllllllllll}
\hline & \multicolumn{3}{c}{ Visual - exhibitions } & \multicolumn{3}{c}{ Visual - escalated } & \multicolumn{4}{c}{ Sound production } \\
\hline Source & $D F$ & $F$ & $P$ & $D F$ & $F$ & $P$ & $D F$ & $F$ & $P$ \\
Group & 2,33 & 2.42 & 0.10 & 2,33 & 2.97 & 0.07 & 2,33 & 0.94 & 0.40 \\
Intrusion & 2,66 & 0.19 & 0.83 & 2,66 & 2.35 & 0.10 & 2,66 & 0.35 & 0.71 \\
G $\times$ I & 4,66 & 1.31 & 0.28 & 4,66 & 1.01 & 0.41 & 4,66 & 0.39 & 0.81 \\
\hline
\end{tabular}




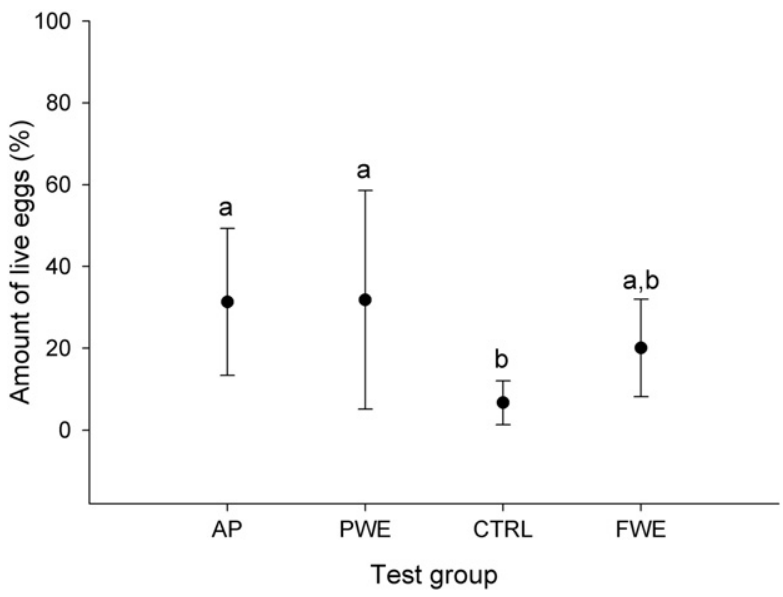

Fig. 1. Variation in egg survival in the different groups. Dots and bars are means and standard deviation. Different letters indicate pairwise significant differences given by ANOVA post-hoc Tukey tests, $\mathrm{P}<0.05$. AP - alloparental; PWE - parental with eggs; FWE - females with eggs; CTRL - control nests without a male or female.

The results obtained in this study show no differences in territorial defense among parental and alloparental males with eggs and males without eggs, as observed by the lack of differences in both visual and acoustic behaviors. This suggests that males defend their nests/shelters in a similar fashion, independently of having their own eggs, foster eggs or no eggs. Curiously, in a recent study parental Lusitanian toadfish males with eggs were found to be more aggressive than males without eggs (Vasconcelos et al., 2010). However, in contrast with the present work, in (Vasconcelos et al., 2010) some males were already guarding embryos, and these showed higher levels of aggressiveness during territorial defense, which may explain the discrepancy with our study.

Parental care in fish mainly consists in nest defense and egg tending, including aeration and cleaning (Gross and Sargent, 1985). Eggs in nests occupied by males presented similar levels of survival and these levels were significantly higher than when eggs were in nests without fish, suggesting similar levels of care between alloparental and parental males. However, we cannot exclude the possibility that egg survival may have been influenced by the simple presence of a fish, i.e. by 'passive care'. Movements inside the nest may have increased egg aeration and fish may possess compounds in the epidermal mucus that might have prevented fungus infection which could have increased egg survival (Knouft et al., 2003). The intermediate levels of egg survival found for nests with females, which do not exhibit parental care, support the argument that the simple presence of a fish inside the nest increases egg survival, although these levels were not significantly different from the ones found for unoccupied nests. This suggests that the significant differences in egg survival between nests with males and nests with no fish are possibly due to active care, pointing to the existence of alloparental behavior in this fish. Nevertheless, we cannot rule out the 'passive care' hypothesis since subject males had larger body sizes than experimental females likely causing larger water movement inside the nest and higher mucus excretion.

Despite the fact that nests with males showed significantly higher egg survival than unoccupied nests, the observed values were still low (c. 30\%). This low survival rate might be explained by the observed detachment of some eggs from the nest, by egg cannibalism or simply by egg death. During the long period of parental care males have decreased opportunities to feed and experience a reduction in physical condition throughout the breeding season (Modesto and Canário, 2003). Thus it would be advantageous to ingest eggs that are nutritionally rich. Consistent with this suggestion, eggs and embryos have been found in the stomach of male midshipmen suggesting they could cannibalize part of the clutch (Sisneros et al., 2009). However, cannibalism represents an advantage to the male when they are able to distinguish their own eggs from foster eggs, selectively consuming the eggs that they have
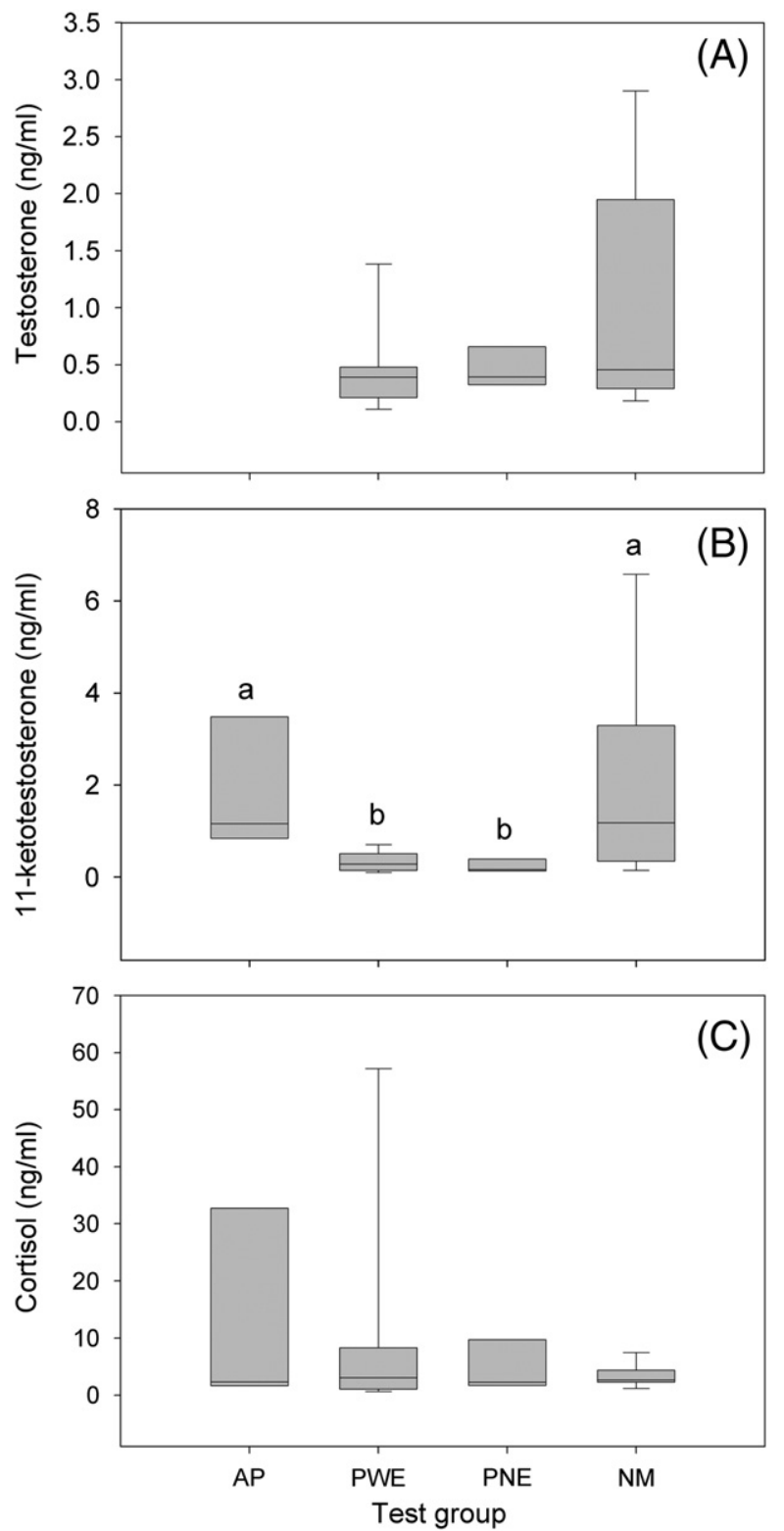

Fig. 2. Variation of (A) testosterone, (B) 11-ketotestosterone and (C) cortisol levels among male groups. Plots show the medians, 10 th, 25 th 75 th, and 90 th percentiles as vertical boxes with errors bars. Different letters indicate pairwise significant differences given by Kruskall-Wallis post-hoc tests, $\mathrm{P}<0.05$. AP - alloparental males; $\mathrm{PWE}$ - parental males with eggs; PNE - parental males with no eggs; NM - non-manipulated males.

not sired. Cases like Pimephales promelas and Gasterosteus aculeatus are some examples of cannibalism and, while the first can distinguish their eggs (Sargent, 1989), G. aculeatus seems not to be able to do that (FitzGerald and van Havre, 1987). According with (Wisenden, 1999), many fish parents do not actively discriminate against non-descendant eggs either because the cost of keeping them is very low or the cost of eliminating them is too high. Alloparental care may be enhanced in species in which females prefer to spawn with males that are already defending nests with eggs (Rohwer, 1978), possibly causing some males to adopt eggs as a tactic to attract females (Sargent, 1989; Unger and Sargent, 1988). Whether Lusitanian toadfish males adopt foster eggs after nest takeovers to enhance mate attraction still needs to be tested.

Our experimental design did not take into account the predation pressure by heterospecifics. Crabs, for example, are typical egg predators that 
rapidly remove all eggs when males abandon their nests in nature (unpublished data). Egg death in ENM was likely caused by fungus (eggs became dark) but would have been much faster in the presence of egg predators. Moreover, we cannot exclude the possibility of differential motivation between parental males (PWE) and alloparental males in excluding predators, such as crabs from the nest, that might have influenced the results of our experiments have they been conducted in the natural habitat.

The lack of differences that we observed in territorial defense behavior among male groups is consistent with the general lack of differences in androgen circulating levels. In fact, our different treatment groups did not differ in T levels, although AP males showed higher levels of $11 \mathrm{KT}$ than the remaining groups. However, they showed a very high variability in $11 \mathrm{KT}$ levels that fell within the range of the circulating levels observed in nature, both in breeding males (non-manipulated male group in this study) and in males in the post-breeding period (Modesto and Canário, 2003). Thus, the presence of early-stage offspring (i.e. own or foster eggs) does not seem to alter androgen levels that would mediate aggression towards intruders.

Although there is a general agreement on the mediation of agonistic behavior and territorial defense displays by $\mathrm{T}$ and especially $11 \mathrm{KT}$ (Oliveira and Gonçalves, 2008), including calling behavior in teleosts (Remage-Healey and Bass, 2005), the function of these hormones during parental care in teleosts is more controversial. In a number of teleosts, androgens have been shown to facilitate courtship and territorial behaviors, but to suppress paternal care (Oliveira et al., 2002; Ros et al., 2004), although exceptions where androgen levels remain elevated through parental care exist (e.g. Knapp et al., 1999; Rodgers et al., 2006). The few studies that have focused on androgen mediation of nest defense during parental care have shown that aggressive behavior of smallmouth bass (Micropterus dolomieu) males towards a predator is not correlated to circulating testosterone (or cortisol) (Hanson et al., 2009). However, in other species (e.g. Neolamprologus pulcher), androgens may facilitate nest defense (Desjardins et al., 2008). In the midshipman androgen levels may reflect a compromise between investment in parental behavior versus continued courtship and/or territoriality (Knapp et al., 1999). This is particularly important in males that can spawn with multiple females over the course of the breeding season such as the Lusitanian toadfish.

Cortisol is a major stress hormone that can increase in plasma due to long-term or acute stress (e.g. Clearwater and Pankhurs, 1997), or it may be quickly released into the plasma in response to agonistic challenges such as territorial intrusions (Remage-Healey and Bass, 2005). Similar plasma levels of this steroid in both experimental animals and non-manipulated males suggests that experimental procedures did not cause increased fish stress and that the lack of differences in territorial defense behavior among treatments was not caused by pool confinement and experimental procedures. Moreover, it suggests that territorial intrusions elicited a similar stress response among the different subject groups. Cortisol data in our study suggest that the presence of eggs in the nest (own or foster) did not affect the stress response induced by the agonistic interaction between the intruders and nesting males.

\section{Conclusion}

This work suggests that Lusitanian toadfish provides alloparental care to foster eggs. During the breeding season males arrive to mating areas in large densities increasing competition for nesting places (Amorim et al., 2010) and nest takeovers are likely to occur upon nest intrusions (Vasconcelos et al., 2010). In this context alloparental care could have evolved if it conferred advantages to the new nest occupant. Further work is needed to prove that the existence of eggs in the nest represents an advantage in mate attraction. It is also still necessary to test to which extent fish movements and the action of skin mucus results in 'passive care', such as observed in the case of nests occupied by females in the present study. [RH]

\section{References}

Alcock, J., 2009. Animal Behavior: An Evolutionary Approach, ninth ed. Sinauer Associates Inc., Sunderland, Massachusetts.

Amorim, M.C.P., Simões, J.M., Fonseca, P.J., Almada, V.C., 2010. Patterns of shelter usage and social aggregation by the vocal Lusitanian toadfish. Mar. Biol. 157, 495-503, http://dx.doi.org/10.1007/s00227-009-1335-6.

Blumer, L.S., 1979. Male parental care in bony fishes. Q. Rev. Biol. 54, 149-161.

Brantley, R.K., Bass, A.H., 1994. Alternative male spawning tactics and acoustic signals in the Plainfin midshipman fish Porichthys notatus Girard (Teleostei, Batrachoididae) Ethology 96, 213-232.

Clearwater, S.J., Pankhurs, N.W., 1997. The response to capture and confinement stress of plasma cortisol, plasma sex steroids and vitellogenic oocytes in the marine teleost, red guarnard. J. Fish Biol. 50 (2), 429-441.

Constanz, G.D., 1985. Alloparental care in the tessellated darter, Etheostoma olmstedi (Pisces: Percidae). Environ. Biol. Fishes 14, 175-183.

Desjardins, J.K., Stiver, K.A., Fitzpatrick, J.L., Milligan, N., van der Kraak, G.J., Balshine, S. 2008. Sex and status in a cooperative breeding fish: behaviour and androgens. Behav. Ecol. Sociobiol. 62, 785-794.

dos Santos, M.E., Modesto, T., Matos, R.J., Grober, M.S., Oliveira, R.F., Canário, A.V.M., 2000. Sound production by the Lusitanian toadfish, Halobatrachus didactylus. Bioacoustics 10, 309-321.

Farmer, M.B., Alonzo, S.H. 2008. Competition for territories does not explain allopaternal care in the tessellated darter. Environ. Biol. Fishes 83 (4), 391-395, http://dx.doi.org/ 10.1007/s10641-008-9359-1.

FitzGerald, G.J., van Havre, N., 1987. The adaptive significance of cannibalism in stickleback (Gasterosteidae: Pisces). Behav. Ecol. Sociobiol. 20, 125-128.

Gray, G.A., Winn, H.E., 1961. Reproductive ecology and sound production of the toadfish Opsanus tau. Ecology 28, 274-282.

Gross, M.R., Sargent, R.C., 1985. The evolution of male and female parental care in fishes. Am. Zool. 25, 807-822

Hanson, K.C., O'Connor, C.M., Van Der Kraak, G., Cooke, S.J., 2009. Paternal aggression towards a brood predator during parental care in wild smallmouth bass is not correlated with circulating testosterone and cortisol concentrations. Horm. Behav. 55, 495-499.

Knapp, R., Wingfield, J.C., Bass, A.H., 1999. Steroid hormones and parental care in the plainfin midshipman fish (Porichthys notatus). Horm. Behav. 35, 81-89.

Knouft, J.H., Page, L.M., Plewa, M.J., 2003. Antimicrobial egg cleaning by the fringed darter (Perciformes: Percidae: Etheostoma crossopterum): implications of a novel component of parental care in fishes. Proc. R. Soc. Lond. B Biol. Sci. 270, 2405-2411.

Manica, A., 2002. Filial cannibalism in teleost fish. Biol. Rev. 77, 261-277.

Modesto, T., Canário, A.V.M., 2003. Morphometric changes and sex steroid levels during the annual reproductive cycle of the Lusitanian toadfish, Halobatrachus didactylus. Gen. Comp. Endocrinol. 131, 220-231.

Oliveira, R.F., Gonçalves, D.M., 2008. Hormones and social behaviour of teleost fish. In: Magnhagen, C., Braithwaite, V.A., Forsgren, E., Kapoor, B.G. (Eds.), Fish Behaviour Science Publishers Inc., Enfield, N.H, pp. 61-150.

Oliveira, R.F., Hirschenhauser, K., Carneiro, L.A., Canário, A.V., 2002. Social modulation of androgen levels in male teleost fish. Comp. Biochem. Physiol. B Biochem. Mol. Biol. 132 (1), 203-215.

Remage-Healey, L., Bass, A.H., 2005. Simultaneous, rapid, elevations in steroid hormones and vocal signaling during playback challenge: a field experiment in Gulf toadfish. Horm. Behav. 47, 297-305.

Rodgers, E.W., Earley, R.L., Grober, M.S., 2006. Elevated 11-ketotestosterone during paternal behavior in the bluebanded goby (Lythrypnus dalli). Horm. Behav. 49, 610-614.

Rohwer, S., 1978. Parent cannibalism of offspring and egg raiding as a courtship strategy. Am. Nat. 112, 429-440.

Ros, A.F.H., Bruintjes, R., Santos, R.S., Canário, A.V.M., Oliveira, R.F., 2004. The role of androgens in the trade-off between territorial and parental behavior in the Azorean rock-pool blenny, Parablennius parvicornis. Horm. Behav. 46, 491-497.

Roux, C., 1986. Fishes of the North-eastern Atlantic and the Mediterranean. In: Whitehead, P.J.P., Bauchot, M.L., Hureau, J.C., Nielsen, J., Tortonese, E. (Eds.), Batrachoididae. UNESCO, Paris, pp. 1360-1361.

Sargent, R.C. 1989. Alloparental care in the fathead minnow, Pimephales promelas: stepfathers discriminate against their adopted eggs. Behav. Ecol. Sociobiol. 25, 379-386.

Sisneros, J.A., Alderks, P.W., Leon, K., Sniffer, B., 2009. Morphometric changes associated with the reproductive cycle and behaviour of the interidal-nesting, male plainfin midshipman fish, Porichthys notatus. J. Fish Biol. 74, 18-36.

Smith, C., Wootton, R.J., 1995. The costs of parental care in teleost fishes. In: Wisenden, B.D. (Ed.), Reviews in Fish Biology and Fisheries, vol. 9. Kluwer Academic Publishers, Netherlands, pp. 45-70.

Taborsky, M., 1985. Breeder-helper conflict in a cichlid fish with broodcare helpers: an experimental analysis. Behaviour 95, 45-75.

Trivers, R.L., 1972. Parental investment and sexual selection. In: Campbell, B. (Ed.), Sexual Selection and the Descent of Man. Aldine-Atherton, Chicago, pp. 136-179.

Unger, L.M., Sargent, R.C., 1988. Alloparental care in the fathead minnow, Pimephales promelas: females prefer males with eggs. Behav. Ecol. Sociobiol. 23, 27-32.

Vasconcelos, R.O., Simões, J.M., Almada, V.C., Fonseca, P.J., Amorim, M.C.P., 2010. Vocal behaviour during territorial intrusions in the Lusitanian toadfish: boatwhistles also function as territorial 'keep-out' signals. Ethology 116, 155-165.

Vasconcelos, R.O., Carriço, R., Ramos, A., Modesto, T., Fonseca, P.J., Amorim, M.C.P., 2012 Vocal behavior predicts reproductive success in a teleost fish. Behav. Ecol. 23, 375-383.

Wisenden, B.D., 1999. Alloparental care in fishes. Rev. Fish Biol. Fish. 9, 45-70. 